\title{
Advanced glycation endproducts are increased in rheumatoid arthritis patients with controlled disease
}

Lodewijk de Groot ${ }^{1 *}$, Helmy Hinkema', Johanna Westra' ${ }^{1}$, Andries J Smit ${ }^{2}$, Cees GM Kallenberg ${ }^{1}$, Marc Bijl and Marcel D Posthumus ${ }^{1}$

\begin{abstract}
Introduction: Advanced glycation end products (AGEs) are produced and can accumulate during chronic inflammation, as might be present in patients with rheumatoid arthritis (RA). AGEs are involved in the development of cardiovascular disease. The aim of this study is to evaluate whether AGEs are increased in patients with longstanding RA and whether AGE accumulation is related to disease activity, disease severity and measures of (premature) atherosclerosis, such as endothelial activation, endothelial dysfunction and intima media thickness (IMT).

Methods: In a cross-sectional study, 49 consecutive RA patients with longstanding disease (median disease duration of 12.3 years (range 9.3 to 15.1)), receiving standard of care, were included and compared with 49 ageand sex-matched healthy controls $(\mathrm{HC})$. AGEs were determined by skin autofluorescence. Disease activity was evaluated by the Disease Activity Score of 28 joints (DAS-28) score and joint damage by modified Sharp-v.d. Heijde score. Endothelial activation (soluble vascular cellular adhesion molecule-1) sVCAM-1, von Willebrand factor (VWF), thrombomodulin), endothelial dysfunction (determined by small artery elasticity (SAE)) and IMT were measured and related to AGE accumulation.

Results: AGEs were increased in RA patients (median 2.4 arbitrary units (a.u.), range 1.6 to 4.2) compared to HC (2.2, 1.3 to 3.8). RA patients had a DAS-28 score of 2.9 (0.8 to 6.9) and a modified Sharp-v.d. Heijde score of 19 (0 to 103). sVCAM-1 and VWF levels were higher in RA patients. SAE was significantly decreased in RA $(3.9 \mathrm{ml} / \mathrm{mmHg}$ (1.4 to 12.2) vs. 6.1 in HC (1.7 to 12.9). IMT did not differ between the two groups. Combining both groups' AGEs correlated with VWF, SVCAM-1 and IMT, and was inversely related to SAE. In RA, AGEs had an inverse relation with SAE, but did not relate to disease activity or radiological damage. In multivariate analysis for both groups, smoking, glucose levels, VWF, SAE and male gender were significantly related to the formation of AGEs.
\end{abstract}

Conclusions: AGEs were increased in RA patients with long-standing disease and without signs of premature atherosclerosis. AGEs were related to endothelial activation and endothelial dysfunction. This supports the hypothesis that in RA AGEs may be an early marker of cardiovascular disease.

Keywords: rheumatoid arthritis, endothelial cell activation, endothelial dysfunction, intima media thickness, advanced glycation end products, atherosclerosis

\footnotetext{
* Correspondence: lodewijk.de.groot@reuma.umcg.nl

'Department of Rheumatology and Clinical Immunology, University Medical

Centre, University of Groningen, Groningen, The Netherlands

Full list of author information is available at the end of the article
} 


\section{Introduction}

Rheumatoid arthritis (RA) is associated with an excess morbidity and mortality due to cardiovascular disease (CVD). In a recent study, the risk for development of cardiovascular disease in RA was comparable with that in diabetics [1]. The excess in morbidity and mortality in RA patients due to CVD cannot be explained by traditional risk factors alone [2]. One of the non-traditional risk factors involved in patients with RA is considered to be chronic inflammation [3].

Chronic inflammation is supposed to accelerate the formation of the atherosclerotic plaque [4-6]. Inflammation results in endothelial activation and dysfunction, which are considered to be the first steps in the process finally resulting in atherosclerosis $[7,8]$. Endothelial cell activation is characterized by up-regulation and release of adhesion molecules, such as von Willebrand Factor (vWF), soluble vascular cell adhesion molecule-1 (sVCAM-1) and thrombomodulin (TM). Endothelial cell activation is followed by endothelial cell dysfunction. This phase is characterized by influx of inflammatory cells into the intima of the vascular wall and movement of smooth muscle cells out of the tunica media into the intima. Mononuclear cells absorb lipoproteins, such as oxidized LDL to form foam cells [6]. This process leads to an increased "stiffness" of the arterial wall, which can be measured by several methods, such as pulse wave analysis (PWA). PWA is a non-invasive method in which the elasticity of the radial artery is calculated by tonometry of the radial artery. PWA has been proven a valid method to identify endothelial dysfunction in RA [8]. Measurement of intima media thickness (IMT) serves as a surrogate marker for atherosclerosis [9].

Chronic inflammation might result in the production of advanced glycation end products (AGEs). Increased levels of AGEs are correlated with the development of future microvascular and macrovascular events in diabetics and non-diabetics [10-12]. AGEs can be quantified by a validated method that determines autofluorescence in the skin [13] and are found in atherosclerotic plaques [14]. AGEs can also be measured in plasma and urine. We deliberately chose measuring AGEs in the skin because AGEs in the skin reflect oxidative stress over a longer period of time compared to AGEs in plasma and urine, which reflect a more acute phase of oxidative stress. In a study in SLE patients, AGEs in the skin proved to be elevated in contrast to AGEs in plasma, which were not elevated [15]. AGEs are formed by cross-linking of proteins, nucleic acids and lipids [16] and can be a ligand for the receptor of AGE (RAGE), which is expressed on neutrophils, macrophages, T-cells and synovial fibroblasts [17]. Other known ligands for RAGE are, for example,
HMGB1 and S100A12. Higher levels of HMGB1 are found in RA and predict mortality after myocardial infarction $[18,19]$. Increased levels of S100A12 are correlated with higher mortality in dialysis patients [20]. Ligation of AGE to RAGE results in NF- $\kappa$ B migration to the nucleus, stimulates transcription of pro-inflammatory genes and leads to up-regulation of endothelial adhesion molecules, such as SVCAM-1. sVCAM-1 expression facilitates adhesion of circulating T-lymphocytes [21]. As such, AGE-RAGE interaction can become a selfmaintaining process, contributing to the development of atherosclerosis $[22,23]$. In RA, AGEs can be generated as a result of oxidative stress during inflammation.

We hypothesize that in longstanding RA, AGEs are increased due to prolonged exposure to oxidative stress and that AGE accumulation is related to endothelial activation, small artery elasticity and IMT, and to markers of disease damage. As such, AGEs might serve as a measure of cumulative inflammation and might be a predictor for CVD in RA patients.

\section{Materials and methods}

\section{Patients and controls}

Consecutive patients fulfilling the American College of Rheumatology (ACR) criteria for RA and having a disease duration of at least 9 years with a maximum of 15 years, who attended the outpatient clinic of the University Medical Center Groningen, were asked to participate in this study.

Exclusion criteria were pregnancy, diabetes mellitus (fasting blood glucose $\geq 7.0 \mathrm{mmol} / \mathrm{L}$ or the use of antidiabetic medications), renal impairment (serum creatinine $>140 \mu \mathrm{mol} / \mathrm{L}$ ), surgery, myocardial infarction or sepsis in the past three months. Fifty patients were included. In addition, age- and sex-matched healthy volunteers were recruited as controls. After inclusion one patient declined further participation for personal reasons. The matched control was, therefore, also removed from further analysis.

Information was obtained from all subjects regarding traditional cardiovascular risk factors, including body mass index (BMI), smoking, blood pressure and lipid levels. Hypertension was defined as systolic blood pressure above $140 \mathrm{mmHg}$ and/or a diastolic blood pressure above $90 \mathrm{mmHg}$ and/or current use of antihypertensive drugs. Dyslipidaemia was defined as plasma cholesterol above $6.21 \mathrm{mmol} / \mathrm{L}$, plasma LDL cholesterol above $3.36 \mathrm{mmol} / \mathrm{L}$, plasma triglycerides above $2.26 \mathrm{mmol} / \mathrm{L}$ or current use of lipid lowering drugs. The study was approved by the local medical ethics committee of the University Medical Center of Groningen and informed consent was obtained from all study participants. 


\section{Blood sampling and analysis}

After an overnight fast, blood was sampled and creatinine, total cholesterol, triglycerides, high density lipoprotein (HDL), low density lipoprotein (LDL), C-reactive protein (CRP), erythrocyte sedimentation rate (ESR) and glucose were measured routinely. Additionally, serum and plasma samples were stored at $-20^{\circ} \mathrm{C}$ for determination of endothelial cell activation markers. Serum levels of sVCAM-1 and thrombomodulin were measured by ELISA according to the manufacturer's instructions (R\&D Systems, Abingdon, UK). Levels of VWF were determined using in-house ELISA as described [24].

\section{Measurement of disease activity}

Disease activity was assessed using the Disease Activity Score for 28 joints (DAS-28 score) $[25,26]$. Ranges of DAS-28 correspond with disease activity. DAS-28 score $<2.6$ indicates remission. DAS-28 score 2.6 to 3.2 indicates low disease activity. DAS-28 score 3.2 to 5.1 indicates moderate disease activity. DAS-28 score above 5.1 is considered high disease activity. Besides the DAS-28, for each patient the ACR/EULAR (American College of Rheumatology/European League Against Rheumatism) 2010 criteria for remission were determined. In these criteria patients are considered to be in remission if they have a maximum of 1 for each of the following: 28-joint count for swollen joints (SJC28) and tender joints (TJC28), CRP ( $\mathrm{mg} / \mathrm{dl})$ and patient's global assessment (0 to 10 scale) [27].

\section{Measurement of functional disability}

Traditionally, disability was assessed using the Health Assessment Questionnaire (HAQ), a score by questionnaire that examines the disabilities that RA-patients encounter in daily living and activities [11]. The final HAQ index ranges from 0 to 3 . Although the mean HAQ of the population rises with age, HAQ scores < 0.3 are considered normal [28].

\section{Measurement of joint damage and cumulative CRP}

To determine the amount of joint damage, we used the van der Heijde modification of the Sharp score. The maximum erosion score for the hands is 160 and for the feet 120; the maximum score for joint space narrowing is 120 for the hands and 48 for the feet, resulting in a maximum total score of 448 [29]. Radiography of the hands and feet were performed when recent radiographs, taken within one year, were not available. Cumulative CRP was calculated by calculating the area under the curve (AUC) by using the trapezoid model [30].

\section{Measurement of small artery elasticity}

After overnight fasting, arterial elasticity was assessed using the CR-2000 (Hypertension Diagnostics, Eagan, MN,
USA) for Pulse-Wave Analysis (PWA). The CR-2000 records and analyzes the blood pressure waveforms data from the Arterial Pulse Pressure Sensor. The distal elasticity of the small arteries (SAE) was estimated from a computerized pulse contour analysis [31,32]. The average of three readings of these parameters taken over 15 minutes was used. These measurements were performed on both the right and left radial artery. The average of the three measurements on each side were taken together and divided by two. Blood pressure was recorded as the average of three measurements on both arms by placing a blood pressure cuff on the opposite arm. Subjects lay in the supine position. For analysis, we used the mean systolic and diastolic blood pressure of these measurements.

\section{Measurement of intima-media thickness}

Details of the method have been described by de Groot et al. [33]. In short, the IMT was determined in the far wall segments of the common carotid artery, carotid bulb and the internal carotid artery. A B-mode image of these segments was obtained from a lateral transducer position, during which the probe was positioned perpendicular to the far wall, showing an intima-media complex over approximately $1 \mathrm{~cm}$. Subjects lay in the supine position. Mean IMT (the mean of the measurements in a segment) and maximum IMT (the highest IMT value found among the segment studied) per segment were calculated. Means of the mean IMT and means of the maximum IMT were calculated as the average for the six carotid segments of the mean value, and of the maximum value per segment, respectively. IMT was measured in a standardized way by the same experienced technicians. Coefficient of variation of IMT measurement of the GCA is approximately $5 \%$ [34].

\section{AGE measurement}

AGEs were measured by using the auto-fluorescence reader (AGE-reader type 214B00102, DiagnOptics BV Groningen, The Netherlands, patent PCT/NL99/00607). The autofluorescence reader illuminates a skin surface of $4 \mathrm{~cm}^{2}$. Emission and excitation light from the skin are measured with a spectrometer. Patients and healthy controls were placed in a seated position and the reader was placed $10 \mathrm{~cm}$ below the elbow fold at the volar side. Autofluorescence is then calculated by dividing the average emitted light intensity per nanometer in the range of 420 to $600 \mathrm{~nm}$ by the average emitted light in the range of 300 to $420 \mathrm{~nm}$ [35]. When patients have visible sunburn no AGE measurement will be performed because of the fact that AGE values are falsely elevated in sunburned skin.

\section{Statistical methods}

Data are expressed as median (range) unless stated otherwise. The sample size of 50 patients was calculated 
on detecting a difference of 0.4 arbitrary units (a.u.) in AGE level between RA and HC with a power of $80 \%$, based on data from an earlier study by Lutgers et al. in diabetics [36]. Two-sample t-tests or Mann-Whitney-U tests were used as appropriate to make comparisons between patients and controls for continuous variables. For categorical variables the chi-square method and for very small expected frequencies the Fisher's exact test were used. Gaussian distribution of the data was analyzed with the D'Agostino-Pearson omnibus normality test. Correlation analysis was performed by Pearson correlation when variables were distributed normally; otherwise the Spearman correlation was used. Predictor analysis for AGE accumulation was performed using multivariate linear regression with forward inclusion of variables with $P<0.10$ in univariate analysis. The probability of $\mathrm{F}$ for entry was 0.05 , which means that variables were included until the $P$-value of the model did not improve anymore. Analyses were performed using Graphpad version 4.032005 (GraphPad Software, San Diego, California, USA) and SPSS version 14.0 (SPSS inc., Chicago, Illinois, USA). Two-sided $P$-values $<0.05$ were considered significant.

\section{Results}

\section{Clinical characteristics of patients and controls}

Fifty RA patients and 50 healthy controls ( $\mathrm{HC}$ ) were included. One patient withdrew for personal reasons; subsequently, the matched control was excluded from analysis. Characteristics of patients and controls, including traditional cardiovascular risk factors, are shown in Table 1. RA patients had a less favorable cardiovascular risk profile: hypertension was more frequent in RA patients compared to HC. Both systolic and diastolic blood pressure were higher in patients. Furthermore, $\mathrm{BMI}$ and the percentage of active smokers were higher in the RA group. Although the proportion of individuals with dyslipidemia did not differ between RA and $\mathrm{HC}$, absolute levels of HDL were lower and triglycerides were higher in RA patients (Table 1).

Disease characteristics of the RA patients are shown in Table 2. Disease activity as measured by DAS-28 score indicated generally minor disease activity, with normal distribution in D'Agostino and Pearson normality test. (median 2.9, range 0.8 to 6.9) and the modified Sharp-v. d. Heijde score was low (19 (0 to 103)) and was not normally distributed. Most RA patients were on diseasemodifying antirheumatic drug (DMARD) therapy, the majority $(63 \%)$ on methotrexate.

AGEs, endothelial cell activation, endothelial dysfunction and intima media thickness

AGEs were increased (median 2.4 a.u., range 1.6 to 4.2 ) in this group of RA patients with longstanding disease
Table 1 Baseline characteristics of patients and controls

\begin{tabular}{|c|c|c|c|}
\hline & $\begin{array}{l}\text { RA patients } \\
\mathrm{N}=49\end{array}$ & $\begin{array}{c}\text { Controls } \\
\mathrm{N}=49\end{array}$ & $\begin{array}{c}P \text { - } \\
\text { value }\end{array}$ \\
\hline Age (years) & 58 (31 to 74$)$ & 59 (29 to 75$)$ & NS \\
\hline Female (\%) & $61 \%$ & $61 \%$ & NS \\
\hline Hypertension (\%) & $42 \%$ & $16 \%$ & 0.012 \\
\hline $\begin{array}{l}\text { Systolic blood pressure } \\
(\mathrm{mmHg})\end{array}$ & $\begin{array}{l}140(100 \text { to } \\
184)\end{array}$ & $\begin{array}{l}130(103 \text { to } \\
157)\end{array}$ & 0.016 \\
\hline $\begin{array}{l}\text { Diastolic blood pressure } \\
(\mathrm{mmHg})\end{array}$ & 79 (55 to 113$)$ & 72 (60 to 96$)$ & 0.038 \\
\hline Body mass index (kg/m2) & $\begin{array}{l}26.6(18.4 \text { to } \\
49.7)\end{array}$ & $\begin{array}{l}24.5(18.9 \text { to } \\
31.6)\end{array}$ & 0.002 \\
\hline Glucose (mmol/L) & 5.3 (4.0 to 6.2 ) & $5.2(4.3$ to 6.9$)$ & NS \\
\hline Creatinine $(\mu \mathrm{mol} / \mathrm{L})$ & 73 (41 to 122$)$ & 71 (53 to 124$)$ & NS \\
\hline Dyslipidemia (\%) & $37 \%$ & $35 \%$ & NS \\
\hline Total cholesterol (mmol/L) & 5.1 (2.9 to 7.1$)$ & 5.0 (2.4 to 6.8$)$ & NS \\
\hline $\begin{array}{l}\text { High density lipoprotein } \\
\text { (mmol/L) }\end{array}$ & 1.4 (0.9 to 2.6) & 1.7 (0.9 to 3.0$)$ & 0.004 \\
\hline $\begin{array}{l}\text { Low density lipoprotein } \\
\text { (mmol/L) }\end{array}$ & 3.1 (1.6 to 5.3$)$ & $3.2(1.6$ to 4.9$)$ & NS \\
\hline Triglycerids (mmol/L) & $\begin{array}{c}1.14(0.53 \text { to } \\
3.38)\end{array}$ & $\begin{array}{l}0.95(0.39 \text { to } \\
4.36)\end{array}$ & 0.047 \\
\hline Active smoking (\%) & $24 \%$ & $10 \%$ & 0.044 \\
\hline
\end{tabular}

Hypertension was defined as: systolic blood pressure $>140 \mathrm{mmHg}$, diastolic blood pressure $>90 \mathrm{mmHg}$ or use of antihypertensive drugs. Dyslipidemia was defined as: total cholesterol $>6.2 \mathrm{mmol} / \mathrm{l}$, low density lipoprotein $>3.2$ $\mathrm{mmol} / \mathrm{L}$, triglycerides $>2.26 \mathrm{mmol} / \mathrm{L}$ or use of lipid lowering drugs. All data are represented as median with range.

in comparison to age- and sex-matched healthy controls (2.2 a.u., range 1.3 to 3.8) (Figure 1). Endothelial cell activation markers were increased in RA as well: sVCAM-1 (491 (range 274 to 909) vs. $354 \mathrm{ng} / \mathrm{ml}$ (range 224 to 691) in HC), vWF (154 (range 49 to 603) vs. 97 $\mathrm{ng} / \mathrm{ml}$ (range 22 to 298 ) in $\mathrm{HC}$ ) and thrombomodulin ( 8.5 (range 1 to 77 ) vs. 3.6 (range 1 to 32 ) $\mathrm{ng} / \mathrm{ml}$ in $\mathrm{HC}$ ) were all significantly elevated in patients (Figure 2). Endothelial dysfunction was present in RA as

\section{Table 2 Patient characteristics of $\mathbf{4 9}$ patients with RA}

\begin{tabular}{lc}
\hline Disease duration (years) & $12.3(9.3$ to 15.1$)$ yrs. \\
Reumatoid factor positive (\%) & $100 \%$ \\
Anti-CCP positive & $79 \%$ \\
DAS-28 & $2.92(0.75$ to 6.9) \\
Remission (ACR/EULAR 2010 criteria) & $18 \%$ \\
HAQ score & $0.18(0.0$ to 1.45$)$ \\
Sharp van der Heijde score & $19(0$ to 103$)$ \\
Medication & MTX (63\%) \\
& SSZ (16\%) \\
& Anti-TNF (22\%) \\
& Rituximab (2\%) \\
& Leflunomide (6\%) \\
& Azathioprine (3\%) \\
None (10\%)
\end{tabular}

Disease duration in years. DAS-28 scores were normally distributed. HAQ and Sharp van der Heijde scores were not normally distributed. 


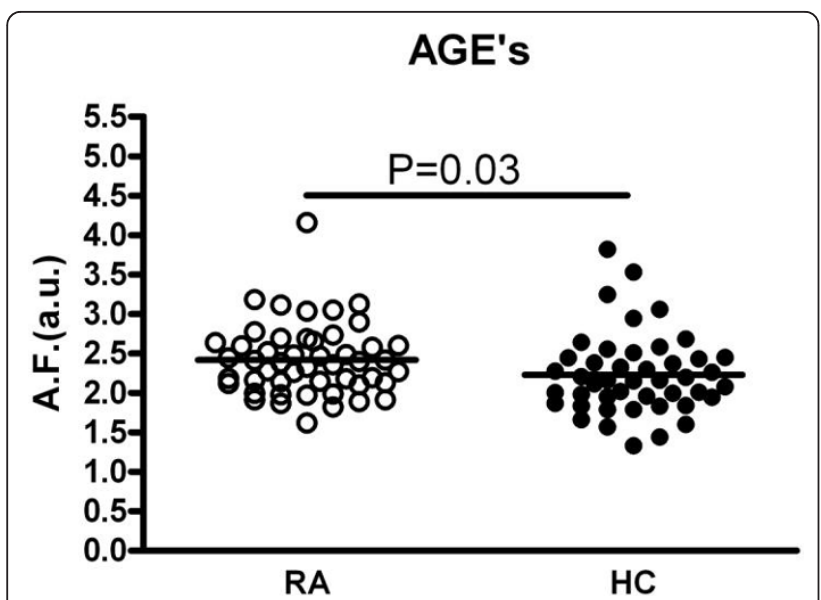

Figure 1 AGE accumulation is significantly increased in RA patients in comparison to healthy controls. The horizontal line denotes the median.

demonstrated by a decreased SAE of 3.9 (range 1.4 to 12.2) in patients vs. 6.1 (range 1.7 to 12.9 ) $\mathrm{ml} / \mathrm{mmHg}$ in HC. In contrast, IMT did not differ between RA patients and $\mathrm{HC}(0.75$ (range 0.28 to 1.80 ) vs. $0.70 \mathrm{~mm}$ (range 0.49 to 1.46 ) in $\mathrm{HC}$ ) (Figure 2).

Additionally, in the total group (RA and $\mathrm{HC}$ ) univariate analysis was performed (Table 3). AGE accumulation was not significantly related to the presence of RA $(P=$ 0.06 ) but did show a significant association with smoking, creatinine, male gender, glucose, age, HDL cholesterol, triglycerides, systolic blood pressure, vWF and IMT. Furthermore, AGE accumulation was inversely related with SAE. In RA patients no correlation was found between AGEs and DAS-28 score, Sharp-vd Heijde score or cumulative CRP. In this group of 49 RA patients, also, no correlation was found between AGEs and markers of endothelial activation or IMT. However, in RA patients AGEs did show an inverse relation with SAE (Figure 3).

\section{Multivariate analysis}

In multivariate analysis with forward inclusion of variables with $P<0.10$ as found in univariate analysis and $\mathrm{F}$ for entry 0.05 , smoking, male gender, glucose level, vWF and SAE proved to be significant factors contributing to the formation of AGEs. (Table 3). The adjusted R square of this model was 0.481 .

\section{Discussion}

Premature atherosclerosis has been shown to be increased in RA [3,37,38]. Moreover, the presence of RA seems to be an independent risk factor for the development of CVD, equal to diabetes mellitus or smoking [1]. The key underlying mechanism is supposed to be the presence of chronic inflammation [6]. As chronic inflammation is represented by the accumulation of AGEs and AGEs contribute to the atherosclerotic process by themselves, in the current study we analyzed whether AGE accumulation occurs in RA patients with longstanding disease and whether AGE accumulation is related to markers of (premature) atherosclerosis and disease characteristics. In accordance with our findings in patients with other systemic autoimmune diseases $[39,40]$, we found increased AGEs levels, as measured by skin auto-fluorescence, in RA patients.

AGEs are generated under the influence of oxidative stress as present in chronic inflammatory diseases like RA. By activating the receptor for AGE (RAGE), translocation of NF- $\kappa \mathrm{B}$ to the nucleus is enhanced. In the nucleus, NF- $\kappa \mathrm{B}$ facilitates the transcription of proinflammatory genes, finally resulting in, for example, the up-regulation of sVCAM-1. In this way a positive feedback loop of AGE-RAGE interaction is established, maintaining an inflammatory status in which AGEs can be formed [17,21,41].

We found that AGEs were inversely related to SAE and positively related to IMT, suggesting that AGEs are involved in the formation of atherosclerotic plaques in RA. The process of atherosclerosis is assumed to start with endothelial activation [5]. Indeed, and in accordance with the results found by others, endothelial activation was increased in our patients, reflected by elevated sVCAM-1, vWF and thrombomodulin serum levels $[42,43]$. In addition, endothelial dysfunction, considered to be the next step in the atherosclerotic process, was present as shown by reduced SAE.

Although endothelial activation and endothelial cell dysfunction were present in our RA patients, IMT was not increased. Other studies, however, did find an increase in IMT in RA [44-50]. First, this discrepancy might be explained by differences in disease activity. In contrast to the patients included in our study, who had low disease activity (median DAS-28 of 2.92), the patients in the studies by Hannawi, Daza and Georgiadis had more active disease, represented by much higher DAS-28 scores of 4.39 (mean), 4.77 (median) and 5.8 (mean), respectively. During moderate to high disease activity edema of the vascular wall might be present. Therefore, it is possible that in patients with active RA and systemic inflammation, IMT not only reflects the presence of atherosclerotic plaques but also thickening of the intima media due to edema, leading to an overestimation of the IMT. Indeed, during follow-up Georgiadis et al. could demonstrate a reduction of IMT in RA patients, associated with a decrease in disease activity [45]. Also, in RA patients in remission (DAS-28 score below 2.60) with an average disease duration of three years, coronary artery disease was not increased compared to controls [51]. Secondly, 


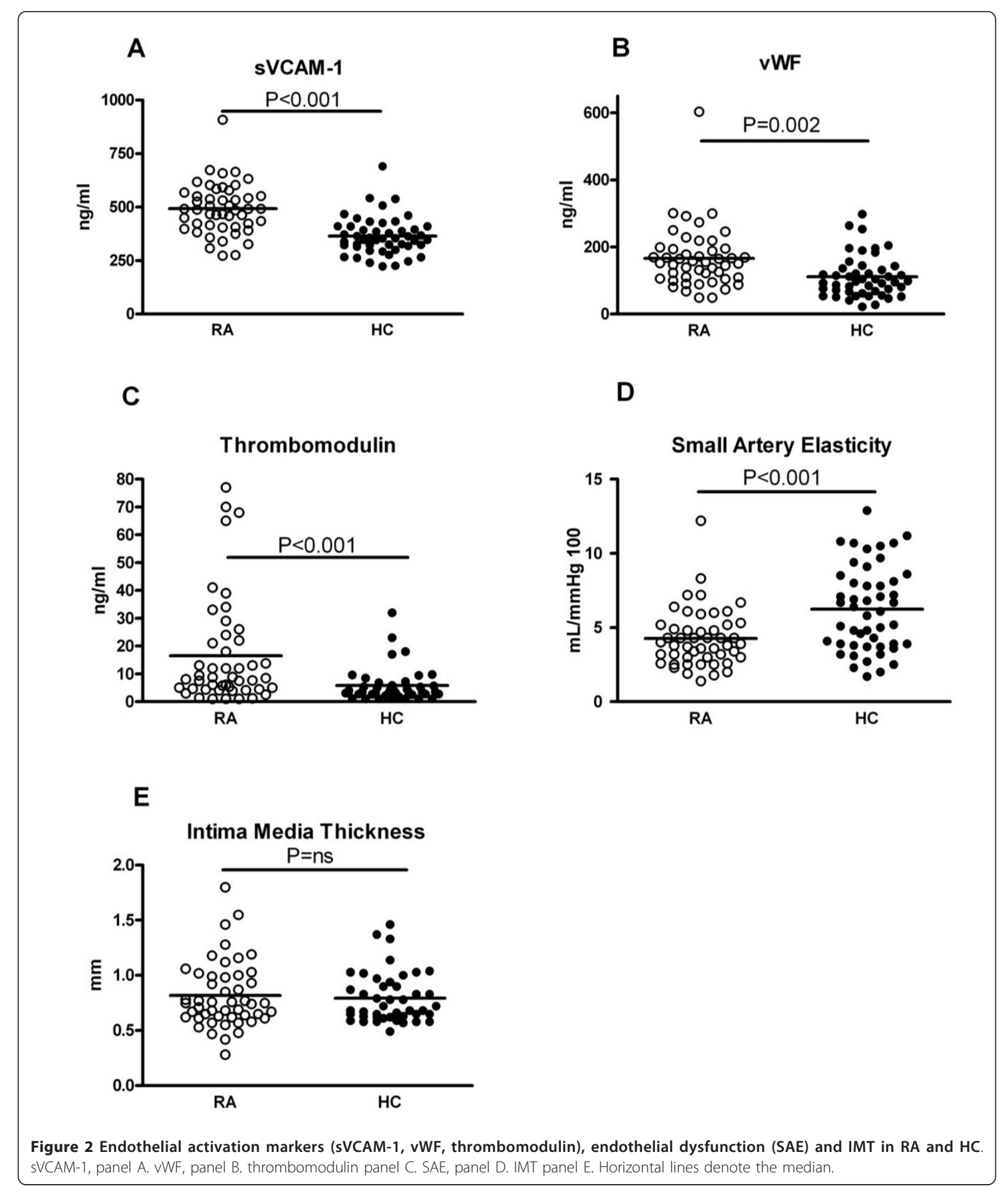

discrepancies in IMT results might be explained by patient selection.

The RA patients included in this study, who were selected solely for having a long disease duration, are representative of our RA cohort and had increased prevalence of several traditional risk factors. This has been shown by others as well [48]. In particular, smoking is known as a risk factor not only for atherosclerosis, but 
Table 3 Univariate and multiple linear regression analysis with AGEs as dependent variable.

\begin{tabular}{|c|c|c|c|c|}
\hline & \multicolumn{2}{|l|}{ Univariate analysis } & \multicolumn{2}{|l|}{ Multivariate analysis } \\
\hline & B (95\% C.I.) & $P$-value & B (95\% C.I.) & $P$-value \\
\hline R.A. & 0.187 (-0.010 to 0.384$)$ & 0.063 & & \\
\hline smoking & 0.433 (0.194 to 0.672 ) & 0.001 & $0.318(0.120$ to 0.516$)$ & 0.002 \\
\hline hypertension & $0.135(-0.069$ to 0.339$)$ & 0.193 & & \\
\hline BMI & 0.011 (-0.010 to 0.032$)$ & 0.304 & & \\
\hline dyslipidemia & $0.124(-0.084$ to 0.331$)$ & 0.239 & & \\
\hline creatinin & 0.011 (0.006 to 0.017 ) & $<0.001$ & & \\
\hline Male gender & 0.451 (0.266 to 0.637$)$ & $<0.001$ & 0.330 (0.262 to 0.508$)$ & $<0.001$ \\
\hline glucose & 0.430 (0.247 to 0.612$)$ & $<0.001$ & 0.196 (0.022 to 0.370$)$ & 0.028 \\
\hline age & 0.020 (0.011 to 0.028$)$ & $<0.001$ & & \\
\hline total cholesterol & $-0.021(-0.123$ to 0.082$)$ & 0.688 & & \\
\hline HDL-cholesterol & $-0.315(-0.536$ to 0.094$)$ & 0.006 & & \\
\hline LDL-cholesterol & $-0.016(-0.135$ to 0.102$)$ & 0.784 & & \\
\hline triglycerides & 0.215 (0.056 to 0.374$)$ & 0.009 & & \\
\hline RR systolic & 0.007 (0.001 to 0.012 ) & 0.030 & & \\
\hline RR diastolic & $0.010(0.000$ to 0.019$)$ & 0.046 & & \\
\hline vWF & 0.003 (0.001 to 0.004$)$ & $<0.001$ & 0.002 (0.001 to 0.003 ) & 0.001 \\
\hline SAE & $-0.069(-0.105$ to -0.034$)$ & $<0.001$ & $-0.035(-0.069$ to -0.002$)$ & 0.039 \\
\hline IMT & 0.429 (0.136 to 0.722$)$ & 0.005 & & \\
\hline
\end{tabular}

Univariate and multiple linear regression analysis in both RA and HC cohorts combined. Multiple linear regression analysis was performed with forward inclusion of variables with $\mathrm{P}<0.10$ in univariate analysis. All data are represented as $\mathrm{B}$ with $95 \%$ confidence interval. The adjusted $\mathrm{R}$-square of this model was 0.481 .

also for RA [52]. In our study of the traditional risk factors for CVD, only smoking attributed to the accumulation of AGEs in multivariate analysis. In contrast to what might be expected, hypertension, BMI and dyslipidemia were not related to AGE accumulation.

Although AGEs were increased in our RA patients, factors other than the presence of RA seem to be more responsible for AGE accumulation. Multivariate analysis revealed that AGE accumulation was independently related to smoking, male gender, glucose level and serum vWF. In a study of 93 RA patients with a

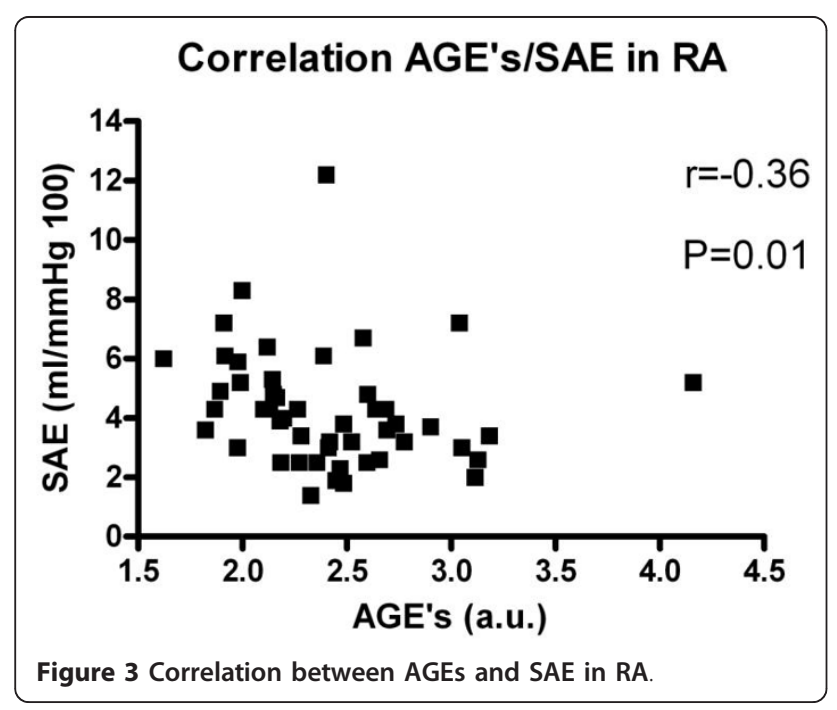

mean age of 61 years, AGEs proved to be increased compared to $\mathrm{HC}$ and osteoarthritis patients. In that study there was no correlation between AGE accumulation and severity of joint destruction, although there was a tendency to higher AGEs in more severe destructive disease [53]. We also did not find a relation between AGEs and disease severity, probably because joint damage in our cohort was quite low, indicating that RA patients in our cohort experienced low disease activity throughout the course of the disease. In a study with etanercept, in 22 RA patients with a mean disease duration of 15.3 years a significant reduction in serum and urinary levels of pentosidine (a sensitive marker for AGEs) was found after six months of treatment with etanercept. In this study, examining patients with high disease activity, a relation with decline in disease activity and pentosidine levels was found, indicating that disease activity is related to AGE formation [54]. In other auto-immune diseases, such as SLE, disease duration of more than 10 years was an independent predictor of AGE accumulation in the skin [39]. We speculate that in the RA patients included in the present study, low inflammatory activity throughout the course of the disease not only hampered occurrence of joint damage but also resulted in low production of AGEs and prevented an increase in IMT. Whether the presence of RA is an important factor in AGE accumulation in more active disease remains unclear and is the subject of future research. 


\section{Conclusions}

Our study shows increased AGE accumulation in RA patients, in particular related to smoking, male sex, glucose levels, endothelial activation and endothelial dysfunction. No relation was found between AGEs and actual disease activity and joint damage. Importantly, AGEs were inversely related to endothelial dysfunction in patients without signs of premature atherosclerosis. This supports the hypothesis that in RA AGEs may be early markers of cardiovascular disease. If so, this might open new therapeutic strategies with AGE breakers, such as alagebrium, a compound that not only degrades AGEs but also improves endothelial dysfunction in an animal model [55].

\begin{abstract}
Abbreviations
AF: Auto Fluorescence; AGEs: advanced glycation endproducts; Anti-CCP: anti-cyclic citrullinated protein; Anti-TNF: anti-tumour necrosis factor; a.u.: arbitrary units; BMI: body mass index; CRP: C-reactive protein; CVD: cardio vascular disease; DAS-28: disease activity score of 28 joins; DMARD: diseasemodifying antirheumatic drug; ESR: erythrocyte sedimentation rate; EULAR: $\mathrm{HAQ}$ : health assessment quality; HC: Healthy Controls; HDL-cholesterol: high density lipoprotein cholesterol; IMT: intima media thickness; LDL-cholesterol: low density lipoprotein cholesterol; MTX: methotrexate; PWA: pulse wave analysis; RA: rheumatoid arthritis; RAGE: receptor for advanced glycation endproducts; RR diastolic: diastolic blood pressure; RR systolic: systolic blood pressure; SAE: small artery elasticity; SVCAM-1: soluble vascular cellular adhesion molecule-1; SSZ: sulfasalazine; TM: thrombomodulin; VWF: von Willebrand factor
\end{abstract}

\section{Acknowledgements}

We thank Dr. Miek van Leeuwen for revising the Sharp-v.d. Heijde scores and Suzanne Arends for advises concerning the statistical methods in the study.

\section{Author details}

'Department of Rheumatology and Clinical Immunology, University Medical Centre, University of Groningen, Groningen, The Netherlands. ²Department of Vascular Disease, University Medical Centre, University of Groningen, Groningen, The Netherlands.

\section{Authors' contributions}

MP and $\mathrm{HH}$ participated in the design of the study. MP, HH, AS and JW participated in the acquisition of the data. LG, CK, MP and MB participated in the analysis and interpretation of the data and drafted the manuscript. All authors read and approved the final manuscript.

\section{Competing interests}

The authors declare that they have no competing interests.

Received: 29 March 2011 Revised: 3 December 2011

Accepted: 14 December 2011 Published: 14 December 2011

\section{References}

1. van Halm VP, Peters MJ, Voskuyl AE, Boers M, Lems WF, Visser M, Stehouwer D, Spijkerman AM, Dekker JM, Nijpels G, Heine RJ, Bouter LM, Smulders YM, Dijkmans BA, Nurmohamed MT: Rheumatoid arthritis versus diabetes as a risk factor for cardiovascular disease: a cross-sectional study, the CARRE investigation. Ann Rheum Dis 2009, 68:1395-1400.

2. Van Doornum S, McColl G, Wicks IP: Accelerated atherosclerosis: An extraarticular feature of rheumatoid arthritis? Arthritis Rheum 2002, 46:862-873.

3. del Rincon ID, Williams K, Stern MP, Freeman GL, Escalante A: High incidence of cardiovascular events in a rheumatoid arthritis cohort not explained by traditional cardiac risk factors. Arthritis Rheum 2001, 44:2737-2745.

4. Quyyumi AA: Inflamed joints and stiff arteries: Is rheumatoid arthritis a cardiovascular risk factor? Circulation 2006, 114:1137-1139.

5. Ross R: Atherosclerosis-an inflammatory disease. N Engl J Med 1999, 340:115-126.

6. Libby P, Ridker PM, Maseri A: Inflammation and atherosclerosis. Circulation 2002, 105:1135-1143.

7. Ridker PM, Hennekens CH, Roitman-Johnson B, Stampfer MJ, Allen J: Plasma concentration of soluble intercellular adhesion molecule 1 and risks of future myocardial infarction in apparently healthy men. Lancet 1998, 351:88-92

8. Van Doornum S, McColl G, Jenkins A, Green DJ, Wicks IP: Screening for atherosclerosis in patients with rheumatoid arthritis: Comparison of two in vivo tests of vascular function. Arthritis Rheum 2003, 48:72-80.

9. Duprez DA, De Buyzere ML, De Backer TL, Veire VD, Clement DL, Cohn JN: Relationship between arterial elasticity indices and carotid artery intimamedia thickness. Am J Hypertens 2000, 13:1226-1232.

10. Gerrits EG, Lutgers HL, Kleefstra N, Graaff R, Groenier KH, Smit AJ, Gans RO, Bilo HJ: Skin autofluorescence: a tool to identify type 2 diabetic patients at risk for developing microvascular complications. Diabetes Care 2008, 31:517-521.

11. Goh SY, Cooper ME: Clinical review: the role of advanced glycation end products in progression and complications of diabetes. J Clin Endocrinol Metab 2008, 93:1143-1152.

12. Semba RD, Ferrucci L, Sun K, Beck J, Dalal M, Varadhan R, Walston J, Guralnik JM, Fried LP: Advanced glycation end products and their circulating receptors predict cardiovascular disease mortality in older community-dwelling women. Aging Clin Exp Res 2009, 21:182-190.

13. Mulder DJ, Water TV, Lutgers HL, Graaff R, Gans RO, Zijlstra F, Smit AJ: Skin autofluorescence, a novel marker for glycemic and oxidative stressderived advanced glycation endproducts: an overview of current clinical studies, evidence, and limitations. Diabetes Technol Ther 2006, 8:523-535.

14. Sakata N, Imanaga Y, Meng J, Tachikawa Y, Takebayashi S, Nagai R, Horiuchi S: Increased advanced glycation end products in atherosclerotic lesions of patients with end-stage renal disease. Atherosclerosis 1999, 142:67-77

15. Nienhuis HL, de Leeuw K, Bijzet J, Smit A, Schalkwijk CG, Graaff R, Kallenberg CG, Bijl M: Skin autofluorescence is increased in systemic lupus erythematosus but is not reflected by elevated plasma levels of advanced glycation endproducts. Rheumatology (Oxford) 2008, 47:1554-1558.

16. Smit AJ, Lutgers $\mathrm{HL}$ : The clinical relevance of advanced glycation endproducts (AGE) and recent developments in pharmaceutics to reduce AGE accumulation. Curr Med Chem 2004, 11:2767-2784.

17. Pullerits R, Bokarewa M, Dahlberg $L$, Tarkowski A: Decreased levels of soluble receptor for advanced glycation end products in patients with rheumatoid arthritis indicating deficient inflammatory control. Arthritis Res Ther 2005, 7:R817-824.

18. Goldstein RS, Bruchfeld A, Yang L, Qureshi AR, Gallowitsch-Puerta M, Patel NB, Huston BJ, Chavan S, Rosas-Ballina M, Gregersen PK, Czura CJ, Sloan RP, Sama AE, Tracey KJ: Cholinergic anti-inflammatory pathway activity and high mobility group box-1 (HMGB1) serum levels in patients with rheumatoid arthritis. Mol Med 2007, 13:210-215.

19. Sorensen MV, Pedersen S, Mogelvang R, Skov-Jensen J, Flyvbjerg A: Plasma high-mobility group box 1 levels predict mortality after ST-segment elevation myocardial infarction. JACC CardiovasC Interv 2011, 4:281-286.

20. Nakashima A, Carrero JJ, Qureshi AR, Miyamoto T, Anderstam B, Barany P, Heimburger $O$, Stenvinkel P, Lindholm B: Effect of circulating soluble receptor for advanced glycation end products (sRAGE) and the proinflammatory RAGE ligand (EN-RAGE, S100A12) on mortality in hemodialysis patients. Clin J Am Soc Nephrol 2010, 5:2213-2219.

21. Lander HM, Tauras JM, Ogiste JS, Hori O, Moss RA, Schmidt AM: Activation of the receptor for advanced glycation end products triggers a p21(ras)dependent mitogen-activated protein kinase pathway regulated by oxidant stress. J Biol Chem 1997, 272:17810-17814.

22. Kume S, Takeya M, Mori T, Araki N, Suzuki H, Horiuchi S, Kodama T, Miyauchi $Y$, Takahashi K: Immunohistochemical and ultrastructural detection of advanced glycation end products in atherosclerotic lesions of human aorta with a novel specific monoclonal antibody. Am J Pathol 1995, 147:654-667. 
23. Schleicher ED, Wagner E, Nerlich AG: Increased accumulation of the glycoxidation product $\mathrm{N}$ (epsilon)-(carboxymethyl)lysine in human tissues in diabetes and aging. J Clin Invest 1997, 99:457-468.

24. de Leeuw K, Sanders JS, Stegeman C, Smit A, Kallenberg CG, Bijl M: Accelerated atherosclerosis in patients with Wegener's granulomatosis. Ann Rheum Dis 2005, 64:753-759.

25. van der Heijde DM, 't Hof MA, van Riel PL, Theunisse LA, Lubberts EW, van Leeuwen MA, van Rijswijk MH, van de Putte LB: Judging disease activity in clinical practice in rheumatoid arthritis: First step in the development of a disease activity score. Ann Rheum Dis 1990, 49:916-920.

26. Prevoo ML, 't Hof MA, Kuper $H H$, van Leeuwen MA, van de Putte $L B$, van Riel PL: Modified disease activity scores that include twenty-eight-joint counts. development and validation in a prospective longitudinal study of patients with rheumatoid arthritis. Arthritis Rheum 1995, 38:44-48.

27. Jacobsson LT, Hetland ML: New remission criteria for RA: 'modern times' in rheumatology-not a silent film, rather a 3D movie. Ann Rheum Dis 2011, 70:401-403.

28. Vita AJ, Terry RB, Hubert HB, Fries JF: Aging, health risks, and cumulative disability. N Engl J Med 1998, 338:1035-1041.

29. van der Heijde DM: Plain X-rays in rheumatoid arthritis: Overview of scoring methods, their reliability and applicability. Baillieres Clin Rheumatol 1996, 10:435-453.

30. Crilly MA, Kumar V, Clark HJ, Scott NW, Macdonald AG, Williams DJ: Arterial stiffness and cumulative inflammatory burden in rheumatoid arthritis: a dose-response relationship independent of established cardiovascular risk factors. Rheumatology (Oxford) 2009, 48:1606-1612.

31. Finkelstein SM, Cohn JN: First- and third-order models for determining arterial compliance. J Hypertens Suppl 1992, 10:S11-14.

32. Watt TB Jr, Burrus CS: Arterial pressure contour analysis for estimating human vascular properties. J Appl Physiol 1976, 40:171-176.

33. de Groot E, Zwinderman AH, van der Steen AF, Ackerstaff RG, Montauban van Swijndregt AD, Bom N, Lie Kl, Bruschke AV: Variance components analysis of carotid and femoral intima-media thickness measurements. REGRESS Study Group, Interuniversity Cardiology Institute of The Netherlands, Utrecht, The Netherlands. Regression Growth Evaluation Statin Study. Ultrasound Med Biol 1998, 24:825-832.

34. Sramek A, Bosch JG, Reiber JH, Van Oostayen JA, Rosendaal FR: Ultrasound assessment of atherosclerotic vessel wall changes: reproducibility of intima-media thickness measurements in carotid and femoral arteries. Invest Radiol 2000, 35:699-706.

35. Meerwaldt R, Graaff R, Oomen PH, Links TP, Jager JJ, Alderson NL, Thorpe SR, Baynes JW, Gans ROB, Smit AJ: Simple non-invasive assessment of advanced glycation endproduct accumulation. Diabetologia 2004, 47:1324-1330.

36. Lutgers HL, Graaff R, Links TP, Ubink-Veltmaat LJ, Bilo HJ, Gans RO, Smit AJ: Skin autofluorescence as a noninvasive marker of vascular damage in patients with type 2 diabetes. Diabetes Care 2006, 29:2654-2659.

37. Avina-Zubieta JA, Choi HK, Sadatsafavi M, Etminan M, Esdaile JM, Lacaille D: Risk of cardiovascular mortality in patients with rheumatoid arthritis: A meta-analysis of observational studies. Arthritis Rheum 2008, 59:1690-1697.

38. Wolfe F, Mitchell DM, Sibley JT, Fries JF, Bloch DA, Williams CA, Spitz PW, Haga M, Kleinheksel SM, Cathy MA: The mortality of rheumatoid arthritis. Arthritis Rheum 1994, 37:481-494.

39. de Leeuw K, Graaff R, de Vries R, Dullaart RP, Smit AJ, Kallenberg CG, Bijl M: Accumulation of advanced glycation endproducts in patients with systemic lupus erythematosus. Rheumatology (Oxford) 2007, 46:1551-1556.

40. de Leeuw K, Nienhuis H, Smit A, Stegeman C, Kallenberg C, Bijl M: Increased accumulation of advanced glycation endproducts in patients with Wegener's granulomatosis. Ann Rheum Dis 2010, 69:625-627.

41. Carroll L, Hannawi S, Marwick T, Thomas R: Rheumatoid arthritis: links with cardiovascular disease and the receptor for advanced glycation end products. Wien Med Wochenschr 2006, 156:42-52.

42. Foster W, Carruthers D, Lip GY, Blann AD: Inflammatory cytokines, endothelial markers and adhesion molecules in rheumatoid arthritis: effect of intensive anti-inflammatory treatment. J Thromb Thrombolysis 2010, 29:437-442.

43. Pemberton PW, Ahmad Y, Bodill H, Lokko D, Hider SL, Yates AP, Walker MG, Laing I, Bruce IN: Biomarkers of oxidant stress, insulin sensitivity and endothelial activation in rheumatoid arthritis: a cross-sectional study of their association with accelerated atherosclerosis. BMC Res Notes 2009, $2: 83$.
44. Gonzalez-Juanatey C, Llorca J, Martin J, Gonzalez-Gay MA: Carotid intimamedia thickness predicts the development of cardiovascular events in patients with rheumatoid arthritis. Semin Arthritis Rheum 2009, 38:366-371.

45. Georgiadis AN, Voulgari PV, Argyropoulou MI, Alamanos Y, Elisaf M, Tselepis AD, Drosos AA: Early treatment reduces the cardiovascular risk factors in newly diagnosed rheumatoid arthritis patients. Semin Arthritis Rheum 2008, 38:13-19.

46. Kumeda $Y$, Inaba M, Goto H, Nagata M, Henmi $Y$, Furumitsu $Y$, Ishimura $E$, Inui K, Yutani Y, Miki T, Shoji T, Nishizawa Y: Increased thickness of the arterial intima-media detected by ultrasonography in patients with rheumatoid arthritis. Arthritis Rheum 2002, 46:1489-1497.

47. Del Rincon I, Freeman GL, Haas RW, O'Leary DH, Escalante A: Relative contribution of cardiovascular risk factors and rheumatoid arthritis clinical manifestations to atherosclerosis. Arthritis Rheum 2005, 52:3413-3423.

48. Daza L, Aguirre M, Jimenez M, Herrera R, Bollain JJ: Common carotid intima-media thickness and von Willebrand factor serum levels in rheumatoid arthritis female patients without cardiovascular risk factors. Clin Rheumatol 2007, 26:533-537.

49. Park YB, Ahn CW, Choi HK, Lee SH, In BH, Lee HC, Nam CM, Lee SK: Atherosclerosis in rheumatoid arthritis: morphologic evidence obtained by carotid ultrasound. Arthritis Rheum 2002, 46:1714-1749.

50. Hannawi S, Haluska B, Marwick TH, Thomas R: Atherosclerotic disease is increased in recent-onset rheumatoid arthritis: a critical role for inflammation. Arthritis Res Ther 2007, 9:R116.

51. Ma NH, Teh CL, Rapaee A, Lau KB, Fong AY, Hi S, Chang BC, Yew KL, Liew HB, Ang CK, Ong TK, Chua SK, Chin RW, Sim KH: Subclinical coronary artery disease in Asian rheumatoid arthritis patients who were in remission: a pilot study. Int J Rheum Dis 2010, 13:223-229.

52. Kallberg H, Ding B, Padyukov L, Bengtsson C, Ronnelid J, Klareskog L, Alfredsson L: Smoking is a major preventable risk factor for rheumatoid arthritis: estimations of risks after various exposures to cigarette smoke. Ann Rheum Dis 2011, 70:508-511.

53. Matsumoto T, Tsurumoto T, Baba H, Osaki M, Enomoto H, Yonekura A, Shindo $H$, Miyata $T$ : Measurement of advanced glycation endproducts in skin of patients with rheumatoid arthritis, osteoarthritis, and dialysisrelated spondyloarthropathy using non-invasive methods. Rheumatol Int 2007, 28:157-160.

54. Kageyama Y, Takahashi M, Nagafusa T, Torikai E, Nagano A: Etanercept reduces the oxidative stress marker levels in patients with rheumatoid arthritis. Rheumatol Int 2008, 28:245-251.

55. Soro-Paavonen A, Zhang WZ, Venardos K, Coughlan MT, Harris E, Tong DC, Brasacchio D, Paavonen K, Chin-Dusting J, Cooper ME, Kaye D, Thomas MC, Forbes JM: Advanced glycation end-products induce vascular dysfunction via resistance to nitric oxide and suppression of endothelial nitric oxide synthase. J Hypertens 2010, 28:780-788.

doi:10.1186/ar3538

Cite this article as: de Groot et al:: Advanced glycation endproducts are increased in rheumatoid arthritis patients with controlled disease. Arthritis Research \& Therapy 2011 13:R205.

\section{Submit your next manuscript to BioMed Central and take full advantage of:}

- Convenient online submission

- Thorough peer review

- No space constraints or color figure charges

- Immediate publication on acceptance

- Inclusion in PubMed, CAS, Scopus and Google Scholar

- Research which is freely available for redistribution

Submit your manuscript at www.biomedcentral.com/submit
C Biomed Central 